\title{
Impaired Ovulation in Mice with Targeted Deletion of the Neuronal Isoform of Nitric Oxide Synthase
}

\author{
Sabra L. Klein, ${ }^{1}$ David Carnovale, ${ }^{5}$ Arthur L. Burnett, ${ }^{2}$ \\ Edward E. Wallach, ${ }^{5}$ Howard A. Zacur, ${ }^{5}$ Julie K. Crone, \\ Valina L. Dawson, ${ }^{3,4}$ Randy J. Nelson, ${ }^{1,3}$ and \\ Ted M. Dawson ${ }^{3,4}$ \\ ${ }^{1}$ Behavioral Neuroendocrinology Group, Department of Psychology, \\ and Departments of ${ }^{2}$ Urology, ${ }^{3}$ Neuroscience, ${ }^{4}$ Neurology, and \\ ${ }^{5}$ Gynecology and Obstetrics, Johns Hopkins University, Baltimore, \\ Maryland, U.S.A.
}

Communicated by S. Snyder. Accepted August 21, 1998.

\begin{abstract}
Background: Nitric oxide (NO) plays an important role in numerous reproductive processes. To date, most studies have assessed the role of NO by using nonspecific pharmacological inhibitors of the precursor to NO, nitric oxide synthase (NOS). These pharmacological NOS inhibitors suppress all isoforms of NOS; thus, the precise contribution of each isoform to female reproductive physiology is unknown. The purpose of this study was to determine the specific role of neuronal NOS (nNOS) in the regulation of ovulation in female mice lacking the gene that encodes for nNOS (nNOS-l-).

Materials and Methods: Ovulation was assessed in wild-type (WT) and nNOS-1- female mice by examining the number of ovarian rupture sites and number of oocytes recovered from the oviducts following mating or exposure to exogenous gonadotropins (i.e., $5 \mathrm{IU}$ pregnant mares serum gonadotropin [PMSG] and $5 \mathrm{IU}$ human chorionic gonadotropin [hCG]). Ovulatory efficiency was determined as the number of ovulated oocytes per number of ovarian rupture sites. To examine whether ovulatory deficits in nNOS $-1-$ mice were due to alterations in central mechanisms, plasma luteinizing
\end{abstract}

hormone (LH) concentrations were assessed in WT and nNOS $-1-$ mice that were challenged with $25 \mathrm{ng}$ of gonadotropin-releasing hormone (GnRH). To determine whether ovulatory deficits in nNOS $-1-$ mice were due to local ovulation processes, nerves innervating the reproductive tract of $\mathrm{WT}$ and $\mathrm{nNOS}-1-$ females were examined for the presence of nNOS protein.

Results: There were substantial fertility deficits in nNOS $-1-$ female mice; the nNOS $-/-$ mice had fewer oocytes in their oviducts following spontaneous and gonadotropin-stimulated ovulation. Pituitary responsiveness to exogenous GnRH challenge was intact in nNOS-1- mice. Dense nNOS protein staining was observed in nerves innervating the reproductive tracts of WT mice.

Conclusions: The reproductive deficits in nNOS $-1-$ females are most likely due to alterations in the transfer of oocytes from the ovaries to the oviducts during ovulation. These results suggest that defects in neuronally derived NO production may contribute to female infertility.
Address correspondence and reprint requests to: Dr. Randy J. Nelson, Department of Psychology, Johns Hopkins University, Baltimore, MD 21218-2686, U.S.A. Phone: (410) 516-8407; Fax: (410) 516-6205; E-mail: rnelson@jhu.edu

\section{Introduction}

Nitric oxide (NO) is a mediator of many reproductive processes, including penile erection, ovulation, and the release of gonadotropin-re- 
leasing hormone (GnRH) (1). Because NO has a very short half-life, it is difficult to measure and manipulate directly; therefore, NO is usually studied indirectly by manipulating the enzymatic precursor to NO, nitric oxide synthase (NOS), which transforms arginine into equal numbers of NO and citrulline molecules. At least three isoforms of nitric oxide synthase (NOS) exist, including an inducible form important for the tumoricidal and bactericidal actions of macrophages (iNOS), an endothelial form important for regulating blood vessel tone (eNOS), and a neuronal form (nNOS) that acts as a putative neurotransmitter in both the central and peripheral nervous systems (2). Each of these three isoforms is encoded by distinct genes (3).

Traditionally, NOS is manipulated using pharmacological inhibitors, such as L-nitroarginine methyl ester (L-NAME), that affect all three isoforms of NOS. To assess the specific role of each NOS isoform in the absence of pharmacological side effects, mice with targeted disruption of nNOS (nNOS-l-), eNOS (eNOS-l-), and iNOS (iNOS-l-) have been developed (4-6). Anecdotal observations of our nNOS -1 - breeding colony suggest that the nNOS $-1-$ mice produce fewer litters than wild-type (WT) animals (approximately $50 \%$ and $100 \%$, respectively). Examination of male reproductive physiology and behavior reveals no deficits that could account for the reduced fertility. Mating behavior of nNOS $-1-$ males is unaffected when paired with estrous WT females, and these males actually exhibit increased persistence in mating behavior when paired for an extended period of time with a nonestrous WT female (7). Physiologically, these males exhibit normal penile erections (8). Accordingly, female fertility and reproductive behavior were assessed to determine the source of the reduced fertility in the nNOS-1colony. Our preliminary data reveal no behavioral difference between nNOS-1- and WT females in lordosis or number of ejaculations elicited by WT males.

NO mediates several aspects of female reproductive physiology. Use of nonspecific NOS inhibitors suggests that NO mediates the pulsatile release of both luteinizing hormone (LH) and GnRH in rats $(9,10)$. NO has also been identified in nerve fibers innervating the ovary, oviduct, uterine horns, and uterocervical junction in rats $(11,12)$. Female rats injected with both a nonspecific NOS inhibitor and human chorionic gonadotropin (hCG) ovulate fewer eggs and have fewer ovarian rupture sites than females exposed either to saline or $N$-methyl-D-arginine $(13,14)$. More recently, in perfused rabbit ovaries, administration of L-NAME significantly reduces the number of ruptured follicles in response to hCG (15). Although these studies suggest that NOS is an important mediator of female reproductive physiology, the specific isoform responsible for these reproductive functions remains unspecified. The purpose of the present study was to determine the specific contribution of nNOS to the regulation of ovulation in female mice lacking the gene that encodes nNOS.

\section{Materials and Methods}

\section{Animals}

Adult ( $>60$ days of age) wild-type (WT) C57BL/6J and neuronal nitric oxide synthase knockout (nNOS-1-) female mice, obtained from the breeding colony at the Johns Hopkins University School of Medicine, were used in this study; these mice were obtained from nNOS-1mice that had been backcrossed to the C57BL/6J strain 3 to 7 times. All animals were individually housed in polycarbonate cages $(28 \times 17 \times 12$ $\mathrm{cm})$ with food and water available ad libitum. Animals were maintained under a 16:8 hr light/ dark cycle (lights on from 0600 to $2200 \mathrm{hr}$ ) with an ambient temperature of $21^{\circ} \pm 2{ }^{\circ} \mathrm{C}$ and relative humidity of $50 \% \pm 5 \%$. For each experiment, animals were randomly numbered and all individuals involved in these studies were blind to the genotype of the experimental mice.

\section{Spontaneous Ovulation}

To assess spontaneous ovulation, vaginal cell samples were collected from WT $(n=9)$ and nNOS $-1-(n=11)$ females between 1400 and $1500 \mathrm{hr}$ to monitor estrous cycles. Vaginal cell cytology was assessed to determine when females were presumably in behavioral estrus. Vaginal samples were transferred to microscope slides that were fixed, stained, and diagnosed for estrous stage (i.e., estrus, diestrus I, diestrus II, or proestrus). Only females exhibiting regular estrous cycles (regardless of cycle length) were used in this experiment. After four regular estrous cycles, proestrous females were paired with WT males in a polycarbonate cage $(28 \times 17 \times 12$ $\mathrm{cm})$ overnight to ensure the occurrence of behavioral estrus and, hence, ovulation. Mating behavior was videotaped for $12 \mathrm{hr}$ from 1900 to $0700 \mathrm{hr}$. Following mating, as determined by the 
presence of a sperm-plug and occurrence of an ejaculation the previous night, females were killed by cervical dislocation 12 to $14 \mathrm{hr}$ following ovulation, and the uterine horns, oviducts, and ovaries were dissected. The time line for this experiment was established on the basis of previous studies suggesting that mouse oocytes are located in the ampulla of the oviduct $10-15 \mathrm{hr}$ following ovulation (16). The number of rupture sites on each ovary was recorded using a dissecting microscope $(\times 25$; Olympus $\mathrm{SO})$, and the oviducts were dissected in M2 media (Specialty Media, Inc., Leveled, NJ) supplemented with hyaluronidase $(300 \mu \mathrm{g} / \mathrm{ml})$. Each oviduct was separated from the ovary and uterine horn. If a cumulus mass was observed in the ampulla of the oviduct, the ampulla was severed and the cumulus mass was released into the supplemented media. If the cumulus mass was not present in the ampulla, the oviduct was flushed with the supplemented media to release oocytes. Oocytes were counted under a dissecting microscope $(\times 40)$ after the hyaluronidase had removed all cumulus cells. Ovulatory efficiency, defined as the percentage of ovulation points derived from mature follicles in a given estrous cycle, was calculated as the number of ovulated oocytes per number of ovarian rupture sites $\times 100$ (17).

\section{Gonadotropin-Stimulated Ovulation}

For gonadotropin-stimulated ovulation, female WT $(n=10)$ and nNOS $-1-(n=10)$ mice received an intraperitoneal (ip) injection of $5 \mathrm{IU}$ pregnant mares serum gondotropin (PMSG; Sigma) at $1500 \mathrm{hr}$ and an ip injection of 5 IU hCG (Sigma) $48 \mathrm{hr}$ later to induce ovulation. The stage of estrus at the time of injection was not accounted for in the present study (18). All females were killed $20 \mathrm{hr}$ after hCG injection (13). The number of oocytes recovered from the oviducts was counted as described above. Rupture sites were not counted because the ovaries were distorted following superovulation with gonadotropins and individual rupture sites could not be accurately assessed with a dissection microscope. Consequently, ovulatory efficiency was not calculated.

\section{Pituitary Responsiveness to Exogenous GnRH}

To determine whether central mechanisms mediating ovulation were altered in these animals, females were challenged with exogenous GnRH and plasma LH concentrations were assessed. Only females exhibiting regular estrous cycles were included in the experiment. Eight WT and 7 nNOS-/- females were lightly anesthetized with methoxyflurane vapors and bled from the retro-orbital sinus into heparinized tubes $(50 \mu \mathrm{l} /$ tube) during diestrus. Blood samples were centrifuged at $2000 \mathrm{rpm}$ for $30 \mathrm{~min}$, and plasma was removed and stored at $-80^{\circ} \mathrm{C}$ for later analysis of plasma LH concentrations using RIA (Diagnostic Products Corp., Los Angeles, CA). Following two additional regular estrous cycles, females received an ip injection of $25 \mathrm{ng}$ of GnRH (Calbiochem, lot \#438654) suspended in $0.1 \mathrm{ml}$ of $0.9 \%$ sterile saline (19). All females received the injection of $\mathrm{GnRH}$ at $1400 \mathrm{hr}$, during diestrus, and 30 min after the GnRH challenge, females were anaesthetized and bled through the retro-orbital sinus into heparinized tubes (50 $\mu$ /tube) (19). Blood samples were centrifuged, and plasma was removed and stored for later analysis of plasma LH concentrations.

\section{Immunocytochemistry for $n N O S$}

To examine the presence of nNOS protein in the reproductive tract of WT and nNOS $-1-$ females, females were killed by $\mathrm{CO}_{2}$ inhalation followed by cervical dislocation, and the reproductive tract was removed en bloc. The uterine horns, ovary, and oviduct were separated and embedded in O.C.T. compound (Sigma). Tissue sections (6 $\mu \mathrm{m})$ were obtained for immunohistochemistry. Rabbit anti-rat nNOS antibody was generated against a synthetic $\mathrm{N}$-terminus peptide (approximately $2 \mathrm{kD}$ ) of rat brain nNOS coupled to keyhole limpet hemocyanin (Alexis Corp., San Diego, CA) for immunohistochemistry as described previously (20). For controls, specimens were processed in the absence of primary antibody or following preincubation of anti-nNOS antibody with excess nNOS protein (21). Immunohistochemical localization of nerves was verified with synaptophysin antibody (Zymed Laboratories, San Francisco, CA) (22).

\section{Statistical Analyses}

Two-tailed $t$-tests were used to assess the number of ovarian rupture sites, the number of oocytes recovered from the oviducts, and ovulatory efficiency of WT and nNOS- $1-$ female mice. MannWhitney $U$-tests were used in cases where the distribution of raw data violated the assumptions of a normal distribution (23). Ovulatory effi- 


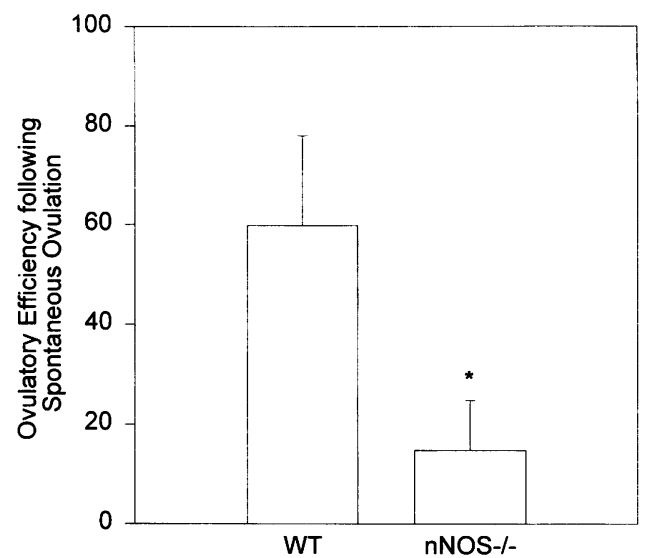

Fig. 1. Ovulatory efficiency (mean \pm SEM) of WT and nNOS $-/-$ females following spontaneous ovulation. Ovulatory efficiency for each female was calculated by dividing the total number of oocytes recovered from the oviducts by the total number of ovarian rupture sites. Ovulatory efficiency is reduced in nNOS $-1-$ compared with WT females. Asterisk indicates $p<0.05$; bars indicate SEM.

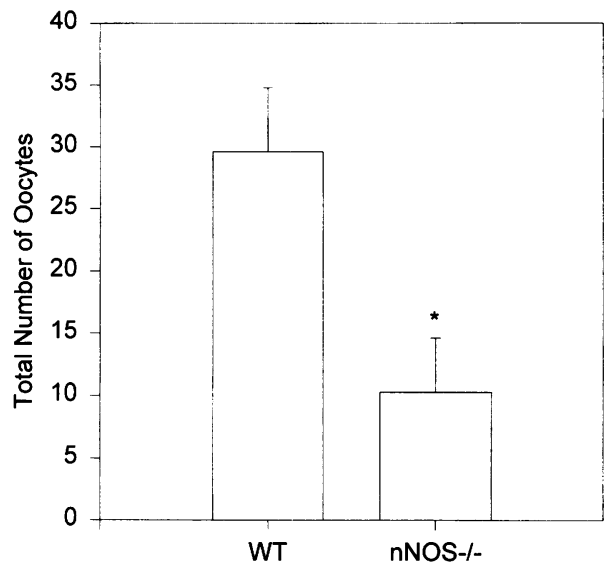

Fig. 2. Number of oocytes (mean \pm SEM) recovered from the oviducts of WT and nNOS-I- females following gonadotropinstimulated ovulation. Each oviduct was separated from the ovary and uterine horn. Oocytes were counted under a dissecting microscope $(\times 40)$ after the hyaluronidase had removed all cumulus cells. nNOS-1- females have fewer oocytes present in their oviducts than WT females following gonadotropin stimulation. Asterisk indicates $p<0.05$; bars indicate SEM.

ciency was determined by dividing the total number of oocytes recovered from each female by the total number of ovarian rupture sites, multiplied by 100. A two-way ANOVA (genotype $\times$ time of sampling) was used to assess plasma LH concentrations. For nonparametric comparisons between groups a chi-square test

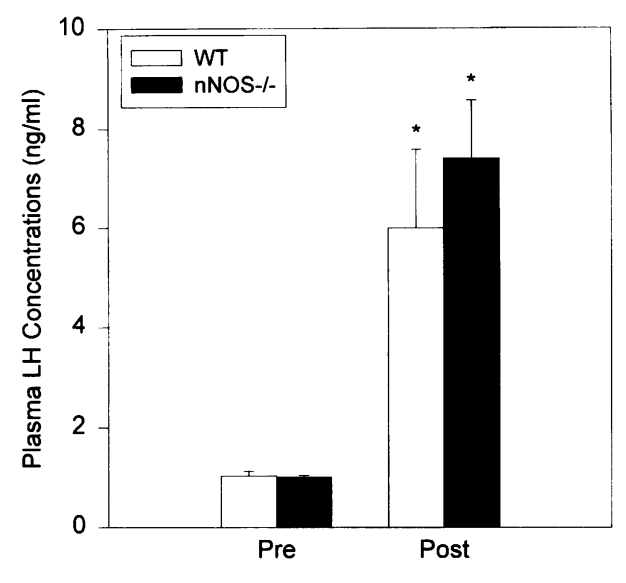

Fig. 3. Plasme LH concentrations (mean \pm SEM) from WT and nNOS $-1-$ females before and after systemic GnRH challenge. Plasma LH concentrations are elevated in both WT and nNOS $-/$ - females following exposure to GnRH. Plasma LH concentrations are not significantly different between WT and nNOS-1- either before or after GnRH challenge. Asterisks indicate $p<0.05$; bars indicate SEM.

was used. Treatment effects were considered statistically significant if $p<0.05$.

\section{Results \\ Ovulatory Efficiency Is Reduced in nNOS-1- Females}

To ascertain whether spontaneous ovulation is altered in nNOS $-1-$ mice, proestrous females were paired overnight with WT males to ensure occurrence of ovulation. Prior to pairing, estrous cyclicity was monitored in these females to determine whether nNOS $-/-$ females enter behavioral estrous (i.e., vaginal proestrus) as frequently as WT females. The average estrous cycle length was equivalent between nNOS-1( $4.55 \pm 0.27$ days) and WT $(5.43 \pm 0.45$ days $)$ females $(p>0.05)$. Ovulatory efficiency was reduced in nNOS $-1-(14.8 \pm 9.96)$ compared with WT $(59.8 \pm 18.2)$ females following mating with a WT male (Fig. $1 ; t=2.32, d f=17, p<$ $0.05)$. Although overall ovulatory efficiency was reduced, there were no statistically significant differences in either the number of rupture sites observed on the ovaries of each female (WT = $9.67 \pm 1.79 ; \mathrm{nNOS}-/-=12.27 \pm 1.65$ ) or the number of oocytes recovered from the oviducts of WT and nNOS $-1-$ females $(\mathrm{WT}=4.44 \pm$ 


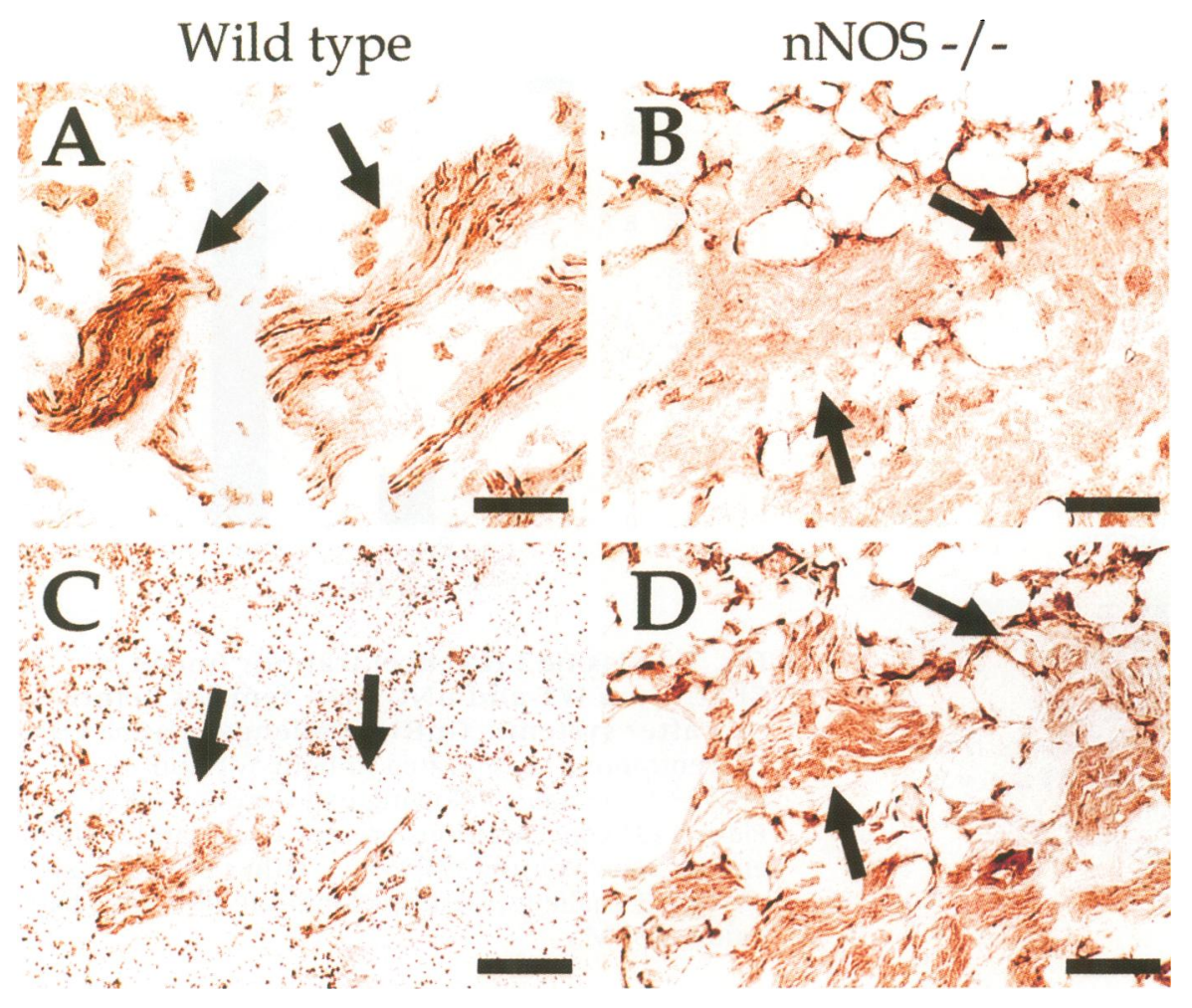

Fig 4. Neuronal NOS immunohistochemical staining of the paracervical ganglion from WT and nNOS-I- female mice. Serial sections from the uterocervical junction are shown. In the WT female, nNOS is localized in the ganglion cells and nerve fibers (A). Conversely, preincubation of nNOS antiserum with nNOS peptide abolishes immunoreactivity $(C)$. In the nNOS-1- female, tissue incubated with nNOS antiserum reveals only nonspecific background staining (B) even though nerve localizations are confirmed with synaptophysin antibody (D). Scale bars, $250 \mu \mathrm{m}$.
1.43; nNOS $-1-=2.00 \pm 1.34)(p>0.05$ in each case). The percentage of females with ovarian rupture sites (WT $=89 \%$; nNOS $-1-=$ $100 \%)$ and oocytes recovered from their oviducts $(\mathrm{WT}=56 \%$; nNOS $-1-=18 \%$ ) was equivalent between WT and nNOS $-1-$ females.

To determine whether gonadotropin-stimulated ovulation is impaired in these mice, females were injected with PMSG and hCG. Significantly more oocytes were recovered from WT $(29.6 \pm$ 5.17) than nNOS-I- (10.3 \pm 4.34$)$ females (Fig. 2; $t=-2.86, d f=18, p<0.01$ ). Also, a higher percentage of WT females $(100 \%)$ had oocytes present in their oviducts than nNOS $-1-$ females $(50 \%)(p<0.05)$.

Plasma LH Concentrations Are Equivalent between $W T$ and $n N O S-1-$ Mice

Following GnRH challenge, plasma LH concentrations increased in both WT and nNOS-1females (Fig. 3; $F(4,24)=32.37, p<0.05)$. Plasma LH concentrations were equivalent between WT and nNOS-1- females both before and after exposure to exogenous GnRH $(p>$ $0.05)$.
Nerves in the Female Reproductive Tract Stain Positive for nNOS Protein in WT Mice

In the uterine horn, ovary, and oviduct, staining with an nNOS antibody confirmed nNOS immunoreactivity in WT, but not nNOS-1- mice (Fig. 4). In the ovary, nerves situated within the stromal fibromuscular layer and the fibromuscular tissue in the thecal cell region near the follicles stained positive for nNOS protein in WT females. Neuronal NOS immunoreactivity was also localized in the nerves of the circular smooth muscle layer at the ampullary and isthmic portions and through the longitudinal smooth muscle layers of the oviduct. In the uterine horns of WT females, nNOS immunoreactivity occurred in nerve fibers coursing beneath the epithelium and in fine nerve fibers distributed throughout the smooth muscle. Also in the uterine horns, the paracervical ganglion, located at the junction of the uterine cervix and the vagina, exhibited nNOS immunoreactivity in WT, but not in nNOS $-1-$ females (Fig. 4A and B). Tissue incubated in the absence of primary antibody did not show staining. Sections incubated with antinNOS antibody preabsorbed with excess nNOS protein also did not show staining (Fig. 4C). 


\section{Discussion}

Our results suggest that in the absence of the neuronal isoform of NOS, female reproductive function is reduced. The nNOS $-1-$ females have reduced ovulatory efficiency following spontaneous ovulation and fewer oocytes ovulated following exposure to exogenous gonadotropins. The reductions in ovulatory efficiency and oocyte recovery are probably due to deficits in local processes because central mechanisms are intact in $\mathrm{nNOS}-1-$ females. The nNOS $-1-$ mice have normal pituitary responsiveness to exogenous GnRH as indicated by equivalent plasma LH concentrations before and after exposure to exogenous GnRH. Thus, the reproductive defects in nNOS $-1-$ females are likely due to alterations in the transport of oocytes from the ovary to the oviduct during ovulation. Consistent with this hypothesis is our observation that the total number of ovarian rupture sites is similar between WT and nNOS-1- females following spontaneous ovulation. Furthermore, nNOS is appropriately situated within select nerve fibers of the reproductive tract of WT females, possibly to facilitate transport of oocytes.

Our studies implicating neuronally derived NO in the regulation of female reproduction contrast with results from studies using nonspecific NOS inhibitors, in which reductions are observed in the number of oocytes recovered from the oviduct, in the number of ovarian rupture sites, and in plasma LH concentrations $(10,13,15,17)$. These differences are probably due to inhibition of all NOS isoforms, including eNOS and iNOS, which are prominently localized in the female reproductive tract where they could regulate female reproductive function $(13,17,24-28)$. Previous studies have demonstrated that in mice the theca interna surrounding the preovulatory follicles stains positive using antibody to human eNOS (28). Accordingly, eNOS may play a role in the transfer of oocytes into the ampulla of the oviduct. Studies from our laboratories are currently examining the role of eNOS in female ovulation. Additionally, iNOS synthesized and released by macrophages affects ovulation. The process of ovulation is reminiscent of an inflammatory reaction because it involves an influx of granulocytes and the release of cytokines within the ovary (26). The proinflammatory cytokine interleukin- $1 \beta$ (IL- $1 \beta$ ), both is present in the ovary and undergoes increased gene expression before ovulation (27). Treatment of perfused rabbit ovaries with IL- $1 \beta$ in vitro induces ovula- tion and oocyte maturation, suggesting that this cytokine is involved in female fertility (17). IL- $\beta$ also facilitates ovarian NOS synthesis, in vitro (24). Additionally, administration of IL-1 $\beta$ to perfused rat ovaries enhances gonadotropin-induced ovulation, whereas further exposure of ovaries to L-NAME inhibits ovulation (13). Taken together, these data suggest that eNOS and iNOS may also be involved in the ovulatory process.

Neuronal NOS appears to play a role in the coordination of events involved in the transport of oocytes from the ovaries to the oviducts during the process of ovulation. Future studies must examine the precise contribution of all isoforms of NOS to ovulation through both the use of mice with targeted deletion of the genes regulating each isoform of NOS and the use of more specific pharmacological inhibitors (29). Clinically, defects in neuronally derived NO production may contribute to female infertility and agents that alter the disposition of NO may have therapeutic potential.

\section{Acknowledgments}

The authors thank Anne Lawler and the staff at the Transgenic Lab at Johns Hopkins University School of Medicine for instruction on oocyte extraction techniques. We thank Beverley Smith for assistance with the LH RIA. Finally, we thank Violette Renard and Sue Yang for technical assistance. This work was supported by grant $\mathrm{MH}$ 57535 (R. J. N.); a New Investigator Grant from the American Foundation for Urological Disease with funds contributed by G. D. Searle, and a Merck Clinician Scientist Award (A. L. B.); and grant NS-33277 and the Paul Beeson Physician Scholars in Aging Research Program (T. M. D.).

\section{References}

1. Nelson RJ, Kriegsfeld LJ, Dawson VL, Dawson TM. (1997) Effects of nitric oxide on neuroendocrine function and behavior. Frontiers Neuroendocrinol. 18: 463-491.

2. Bredt DS, Snyder SH. (1994) Nitric oxide: a physiologic messenger molecule. Annu. Rev. Biochem. 63: 175-195.

3. Lowenstein CJ, Snyder SH. (1994) Purification, cloning, and expression of nitric-oxide synthase. Methods Enzymol. 233: 264-269.

4. Huang PL, Dawson TM, Bredt DS, Snyder SH, Fishman MC. (1993) Targeted disruption of the neuronal nitric oxide synthase gene. Cell 75: 1273-1286. 
5. MacMicking JD, Nathan C, Hom G, et al. (1995) Altered responses to bacterial infection and endotoxic shock in mice lacking inducible nitric oxide synthase. Cell 81: 641-650.

6. Wilson RI, Yanovsky J, Gödecke A, Stevens DR, Schrader J, Haas HL. (1997) Endothelial nitric oxide synthase and LTP. Nature 386: 338.

7. Nelson RJ, Demas GE, Huang PL, et al. (1995) Behavioural abnormalieits in male mice lacking neuronal nitric oxide synthase. Nature 378: 383386.

8. Burnett AL, Nelson RJ, Calvin DC, et al. (1996) Nitric oxide-dependent penile erection in mice lacking neuronal nitric oxide synthase. Mol. Med. 2: 288-296.

9. Moretto M, López FJ, Negro-Vilar A. (1993) Nitric oxide regulates luteinizing hormone-releasing hormone secretion. Endocrinology 133: 2399-2402.

10. Rettori V, Belova N, Dees WL, Nyberg CL, Gimeno M, McCAnn SM. (1993) Role of nitric oxide in the control of luteinizing hormone-releasing hormone release in vivo and in vitro. Proc. Natl. Acad. Sci. U.S.A. 90: 10130-10134.

11. Grozdanovic Z, Mayer B, Baumgarten HG, Brüning G. (1994) Nitric oxide synthase-containing nerve fibers and neurons in the genital tract of the female mouse. Cell Tissue Res. 275: 355-360.

12. Jarrett WA, Price GT, Lynn VJ, Burden HW. (1994) NADPH-diaphorase-positive neurons innervating the rat ovary. Neurosci Lett. 177: 47-49.

13. Bonello N, McKie K, Jasper M, et al. (1996) Inhibition of nitric oxide: effects on interleukin- $1 \beta$ enhanced ovulation rate, steroid hormones, and ovarian leukocyte distribution at ovulation in the rat. Biol. Reprod. 54: 436-445.

14. Shukovski L, Tsafriri A. (1994) The involvement of nitric oxide in the ovulatory process in the rat. Endocrinology 135: 2287-2290.

15. Hesla JS, Chang TSK, Preutthipan S, Wallach EE, Maguire MP, Dharmarajan AM. (1997) Nitric oxide modulates human chorionic gonadotropin-induced ovulation in the rabbit. Fertil. Steril. 67: $48-552$.

16. Rafferty KA. (1970) Methods in Experimental Embryology of the Mouse. Baltimore: Johns Hopkins University Press.

17. Takehara Y, Dharmarajan AM, Kaufman G, Wallach EE. (1994) Effect of interleukin-1 $\beta$ on ovulation in the in vitro perfused rabbit ovary. Endocrinology 134: 788-1793.
18. Redina OE, Amstislavsky SY, Maksimovsky LF. (1994) Induction of superovulation in DD mice at different stages of the oestrous cycle. J. Reprod. Fertil. 102: 263-267.

19. Collins TJ, Parkening TA, Smith ER. (1981) Plasma and pituitary concentrations of $\mathrm{LH}, \mathrm{FSH}$, and prolactin after injection of GnRH in aged female C57BL/6 mice. Neurobiol. Aging 2: 125-131.

20. Herdegen T, Brecht W, Kummer W, et al. (1993) Long-lasting expression of JUN and KROX transcription factors and nitric oxide synthase in intrinsic neurons of the rat brain following axotomy. J. Neurosci.13: 4130-4145.

21. Roskams AJ, Bredt DS, Dawson TM, Ronnett GV. (1994) Nitric oxide mediates the formation of synaptic connections in developing and regenerating olfactory receptor neurons. Neuron 13: 289-299.

22. Rehman J, Chenven E, Brink P, et al. (1997) Diminished neurogenic but not pharmacological erections in the 2- to 3-month experimentally diabetic F-344 rat. Am. J. Physiol. 272: H1960H1971.

23. Hays WL. (1994). Statistics. Fort Worth: Harcourt Brace.

24. Ben-Shlomo I, Kokia E, Jackson MJ, Adashi EY, Payne DW. (1994) Interleukin-1 $\beta$ stimulates nitrite production in the rat overy: evidence for heterologous cell-cell interaction and for the insulin-mediated regulation of the inducible isoform of nitric oxide synthase. Biol. Reprod. 51: 310-318.

25. Cavender JL, Murdoch WJ. (1988) Morphological studies of the microcirculatory system of periovulatory ovine follicles. Biol. Reprod. 39: 989-997.

26. Epsey LL. (1980) Ovulation as an inflammatory reaction-a hypothesis. Biol. Reprod. 22: 73-106.

27. Hurwitz A, Hernandex ER, Payne DW, Dharmarajan AM, Adashi Ey. (1992) Interleukin-1 is both morphogenic and cytotoxic to cultured rat ovarian cells: obligatory role for heterologous, contact-independent cell-cell interactions. Endocrinology 131: 1643-1649.

28. Powers RW, Chen L, Russell PT, Larsen WJ. (1995) Gonadotropin-stimulated regulation of blood-follicle barrier is mediated by nitric oxide. Am. J. Physiol. 269: E290-E298.

29. Demas GE, Eliasson MJL, Dawson TM, et al. (1997) Inhibition of neuronal nitric oxide synthase increases aggressive behavior in mice. $\mathrm{Mol}$. Med. 3: 610-616. 